\title{
The nuclear receptor tailless induces long-term neural stem cell expansion and brain tumor initiation
}

\author{
Hai-Kun Liu, ${ }^{1}$ Ying Wang, ${ }_{1}^{1}$ Thorsten Belz, ${ }_{1}^{1}$ Dagmar Bock, ${ }^{1}$ Andrea Takacs, ${ }^{1}$ Bernhard Radlwimmer, ${ }^{2}$ \\ Sebastian Barbus, ${ }^{2}$ Guido Reifenberger, ${ }^{3}$ Peter Lichter, ${ }^{2}$ and Günther Schütz ${ }^{1,4}$ \\ ${ }^{1}$ Division of Molecular Biology of the Cell I, German Cancer Research Center (DKFZ), Heidelberg 69120, Germany; ${ }^{2}$ Division of \\ Molecular Genetics, German Cancer Research Center (DKFZ), Heidelberg 69120, Germany; ${ }^{3}$ Department of Neuropathology, \\ Heinrich-Heine-University, Düsseldorf 40225, Germany
}

\begin{abstract}
Malignant gliomas are the most common primary brain tumors, and are associated with frequent resistance to therapy as well as poor prognosis. Here we demonstrate that the nuclear receptor tailless (Tlx), which in the adult is expressed exclusively in astrocyte-like $B$ cells of the subventricular zone, acts as a key regulator of neural stem cell (NSC) expansion and brain tumor initiation from NSCs. Overexpression of Tlx antagonizes age-dependent exhaustion of NSCs in mice and leads to migration of stem/progenitor cells from their natural niche. The increase of NSCs persists with age, and leads to efficient production of newborn neurons in aged brain tissues. These cells initiate the development of glioma-like lesions and gliomas. Glioma development is accelerated upon loss of the tumor suppressor p53. Tlx-induced NSC expansion and gliomagenesis are associated with increased angiogenesis, which allows for the migration and maintenance of brain tumor stem cells in the perivascular niche. We also demonstrate that $T l x$ transcripts are overexpressed in human primary glioblastomas in which Tlx expression is restricted to a subpopulation of nestin-positive perivascular tumor cells. Our study clearly demonstrates how NSCs contribute to brain tumorgenesis driven by a stem cell-specific transcription factor, thus providing novel insights into the histogenesis and molecular pathogenesis of primary brain tumors.
\end{abstract}

[Keywords: Tailless; neural stem cells; glioblastoma; mouse model]

Supplemental material is available at http://www.genesdev.org.

Received October 2, 2009; revised version accepted February 22, 2010.

The subventricular zone olfactory bulb (SVZ-OB) system is the major site where neurogenesis takes place in the adult mammalian brain. Neural stem cells (NSCs) corresponding to astrocyte-like type B cells in the adult SVZ give rise to transient amplifying type $\mathrm{C}$ cells, which in turn differentiate into type A cells (neuroblasts) that migrate to the $\mathrm{OB}$ through the rostral migratory stream (RMS) and then become mature local interneurons (Alvarez-Buylla and Garcia-Verdugo 2002). The SVZ has long been suggested as the site of origin of gliomas (Smyth and Stern 1938; Globus and Kuhlenbeck 1942; Vick et al. 1977). Recent studies suggested that a small subpopulation of tumor cells, the so-called brain tumor stem cells (BTSCs), are responsible for driving the growth of malignant gliomas (Ignatova et al. 2002; Hemmati et al. 2003; Singh et al. 2003, 2004; Galli et al. 2004). Furthermore, BTSCs have been implicated in the intrinsic resistance of gliomas to radiation therapy, since these cells may

${ }^{4}$ Corresponding author.

E-MAIL g.schuetz@dkfz-heidelberg.de; FAX 49-6221-423470.

Article is online at http://www.genesdev.org/cgi/doi/10.1101/gad.560310. preferentially activate the DNA damage checkpoint in response to ionizing radiation (Bao et al. 2006a). Similarities in expression profiles and functional properties between BTSCs and NSCs (Vescovi et al. 2006) support the idea that gliomas may arise from the SVZ NSCs.

On the basis of increasing knowledge of important tumor suppressors and oncogenes in brain tumors, genetically modified mouse models have been developed to explore the functional roles of genetic alterations found in human patients (Fomchenko and Holland 2006). Genetic modifications targeted to neural stem/progenitor cells have been suggested as an efficient means to induce gliomas in vivo (Holland et al. 2000; Zhu et al. 2005). The latter analysis, based on mutations in the NF-1 and p53 gene using GFAP-driven Cre recombinase, in particular, suggests that gliomas originate from NSCs (Zhu et al. 2005). However, none of those animal studies has shown that malignant gliomas arise directly from multipotent NSCs (Stiles and Rowitch 2008). Recently, it was reported that nestin-expressing cells are the origin of tumors using mutations in the $p 53$ and NF-1 gene generated by a nestin gene-dependent Cre recombinase fused with the modified 
ligand-binding domain of the estrogen receptor CreERT2 (Alcantara Llaguno et al. 2009). It should be remembered, however, that the nestin gene is expressed in stem and progenitor cells as well as in the quiescent ependymal cells (Doetsch et al. 1997).

The orphan nuclear receptor tailless (Tlx, NR2E1) is expressed in the periventricular neurogenic zone during mouse embryonic development (Monaghan et al. 1995). Tlx mutant animals survive, but suffer specific anatomical deficits in the cortex and the limbic system and lack adult NSCs (Monaghan et al. 1997; Shi et al. 2004). We showed recently that $\mathrm{Tlx}$ is expressed exclusively in astrocyte-like B cells in the adult SVZ, which strongly suggests that the Tlx promoter is a useful tool to introduce genetic modifications specifically into NSCs. Inactivation of the Tlx gene in the adult SVZ leads to loss of the self-renewal ability of adult NSCs (Liu et al. 2008), suggesting that Tlx is a key regulator of NSC maintenance. Strikingly, a series of studies based on gene expression profiling showed that Tlx is overexpressed in various types of human brain tumors, including astrocytomas and ependymomas (Taylor et al. 2005; Modena et al. 2006; Phillips et al. 2006; Sim et al. 2006; Sharma et al. 2007; Parsons et al. 2008). However, none of these studies investigated the role of Tlx in glioma formation. We and others have shown that the tumor suppressor Pten (phosphatase and tensin homolog), which is frequently mutated in malignant gliomas, is a direct target of Tlx (CL Zhang et al. 2006; Liu et al. 2008). This finding, together with the role of Tlx in adult NSCs, suggests that Tlx may play an important role in brain tumor initiation from the SVZ.

In this study, we demonstrate that NSC-specific overexpression of Tlx using bacterial artificial chromosome (BAC)-based technology is sufficient to induce NSC expansion and glioma-like lesions in the adult mouse brain. These lesions progress to invasive gliomas when p53 function is additionally inactivated. In addition, we provide evidence that Tlx is overexpressed, and that its gene, $N R 2 E 1$, is increased in copy number in a fraction of primary glioblastomas from patients. These findings also suggest an important role of Tlx in glioma pathogenesis and BTSC biology.

\section{Results}

\section{Generation of Tlx-overexpressing (Tlx-OE) mice}

To investigate the consequences of Tlx overexpression, we used BAC-based transgenesis for generation of Tlx-OE mice. The BAC contains $104 \mathrm{~kb}$ of $5^{\prime}$ flanking sequences and $22 \mathrm{~kb}$ of $3^{\prime}$ flanking sequences of the Tlx gene, and no other gene was found in this BAC (Liu et al. 2008). We assayed four lines with different copy numbers of the transgene-two lines with one copy, and two lines with two copies (Southern blot) (data not shown). The brains of the +1 copy line are indistinguishable from wild-type littermate mice, but both of the +2 copy lines lack part of the septum (Supplemental Fig. S1), which implies that this phenotype is not caused by the integration of the transgene. Tlx has been shown to be involved in patterning during forebrain development (Stenman et al. 2003), which may explain the septum phenotype. In this study, we focus on the phenotype of Tlx overexpression in the adult brain. To measure the expression level of Tlx mRNA in different lines, we performed real-time PCRbased gene expression analysis using RNA isolated from the SVZ dissected by laser-captured microdissection (Liu et al. 2008). Tlx mRNA expression levels in the SVZ showed copy number dependence between different lines (Fig. 1A). Immunohistochemical (IHC) analysis in the adult mouse SVZ using a Tlx-specific antibody revealed stronger expression in the line with two additional copies (indicated as Tlx-OE) (Fig. 1B). We showed that Tlx is expressed exclusively by astrocyte-like B cells in the SVZ of the adult mouse brain (Liu et al. 2008). Here we demonstrate that GFAP, which is a B-cell-specific marker in the adult SVZ (Doetsch et al. 1999), is coexpressed with Tlx in the SVZ of Tlx-OE mice (Supplemental Fig. S2A, arrows). NG2 and olig2 have been reported to be expressed in type C cells that can give rise to neurons and oligodendrocytes, respectively (Aguirre et al. 2004; Menn et al. 2006). We demonstrate that Tlx expression in Tlx-OE mice is still restricted to the type B cells. We did not observe any colocalization of Tlx and these two C-cell markers in the SVZ of adult Tlx-OE mice (Supplemental Fig. S2B,C). As cell markers, doublecortin (DCX) and polysialylated neural adhesion cell molecules (PSANCAM) were used to identify whether Tlx is expressed in A cells in Tlx-OE mice (Doetsch et al. 1997). None of

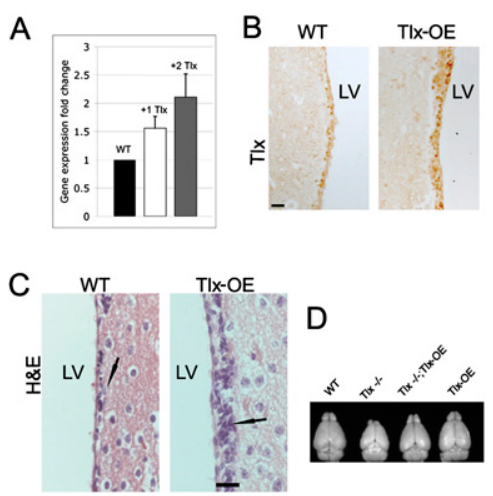

Figure 1. Characterization of Tlx-OE mice. (A) Quantitative PCR analysis of Tlx mRNA in microdissected SVZ cells of wildtype and transgenic mice with one or two additional Tlx gene copies. Note that expression of Tlx mRNA is correlated with the copy number of the Tlx gene $(n=3$, mean \pm standard deviation [SD]). (B) The adult SVZ of Tlx-OE mice $(+2$ copies of Tlx transgene) and wild-type controls were stained by Tlx antibody. Note more Tlx-expressing cells and higher intensity of Tlx staining in the SVZ of Tlx-OE mice. Bar, $20 \mu \mathrm{m}$, if not otherwise indicated. $(C)$ Hematoxylin and eosin $(\mathrm{H} \& \mathrm{E})$ staining of coronal sections from control and Tlx-OE mice. Note a higher cell density in the SVZ of Tlx-OE mice (arrow). (D) Brains isolated from adult age-matched wild-type, $\mathrm{Tlx}^{-1-}, \mathrm{Tlx}^{-1-}$; Tlx$\mathrm{OE}$, and Tlx-OE mice. Note that Tlx overexpression rescues the reduced brain size of $\mathrm{Tlx}^{-/-}$mice. 
the Tlx-expressing cells express DCX or PSA-NCAM, suggesting that A cells do not express Tlx (Supplemental Fig. S2D,E). Platelet-derived growth factor receptor- $\alpha$ (PDGFR $\alpha$ ) was found to be expressed in a subpopulation of type B cells (Jackson et al. 2006). We found that some of the PDGF $\alpha$-expressing cells also express Tlx in Tlx-OE SVZ, suggesting that Tlx is also expressed by these type of B cells (Supplemental Fig. S2F, arrows). These results again demonstrate overexpression of the Tlx gene in a manner expected from the endogenous gene. Histological analysis of the brain from Tlx-OE mice showed a higher cell density in the SVZ (Fig. 1C), suggesting an increase in cell proliferation. To investigate whether the transgene is functional, like the endogenous Tlx gene, we bred the Tlx-OE mice into the Tlx-null $\left(\mathrm{Tlx}^{-1-}\right)$ mouse background (Monaghan et al. 1997). Tlx-OE;Tlx ${ }^{-/-}$mice displayed a phenotype indistinguishable from wild-type mice, with the size and histology of the brain being identical to wild-type mice (Fig. 1D; data not shown).

\section{Overexpression of Tlx leads to an increase of NSC number and of neurogenesis in the adult brain}

To analyze stem/progenitor cell behavior upon Tlx overexpression in vivo, we first followed cell proliferation by Ki67, an established proliferation marker, to analyze stem/progenitor cell proliferation in the mutant mice. We found that the Ki $67^{+}$cell number is increased in the SVZ of Tlx-OE mice (Fig. 2A), which indicates increased proliferation caused by Tlx overexpression in astrocytelike B cells. To confirm these results, Tlx-OE and control adult mice were injected with bromodeoxyuridine (BrdU) and sacrificed $2 \mathrm{~h}$ after injection, and $\mathrm{BrdU}^{+}$cells were counted in the SVZ. The number of BrdU ${ }^{+}$cells in the Tlx-OE SVZ was almost twofold higher than in wild-type mice (Fig. 2B), which suggests that Tlx is a positive regulator of cell proliferation. We also found a significant increase of $\mathrm{BrdU}^{+}$cells in the one-copy transgenic line (data not shown), which confirms the findings from the Tlx-OE mice. The SVZ NSCs give rise to transient amplifying type $\mathrm{C}$ cells, which in turn differentiate into type A cells (neuroblasts) that migrate to the OB through the RMS (Alvarez-Buylla and Garcia-Verdugo 2002). We further analyzed the proportion of $\mathrm{Ki}^{-} 7^{+}$cells in the wildtype and Tlx-OE adult mouse SVZ by staining with GFAP, DCX costained with Ki67. No significant changes were found in the percentage of proliferating B, A, and C cells (Fig. 2C; Supplemental Fig. S3). To investigate whether overexpression of Tlx in NSCs affects the neurogenic process in the SVZ-OB system, DCX, a type A cell marker, was used to study the consequence of Tlx overexpression in B cells. We found that the number of $\mathrm{DCX}^{+}$cells was increased significantly in both the SVZ and the OB RMS of Tlx-OE mice (Fig. 2D,E), indicating an increase of adult neurogenesis in the SVZ-OB system by Tlx overexpression in NSCs. This result also suggests that overexpression of Tlx does not block the differentiation of the SVZ NSCs in vivo.

We showed that overexpression of Tlx in NSCs leads to an increase of cell proliferation in the adult SVZ. How- ever, it remains unclear whether the number of NSCs is increased consecutively. Several studies reported that the slowly dividing, label-retaining cells (LRCs) correspond to the resident stem cell population (Bickenbach 1981; Morris and Potten 1994; Jackson et al. 2006). Therefore, BrdU was administered in the drinking water for $1 \mathrm{wk}$ and then removed for $3 \mathrm{wk}$. This is sufficient time for the labeled C and A cells to migrate to the OB (Jackson et al. 2006; Colak et al. 2008). In this experiment, the line with one additional copy was also included. We found a significant increase of $\mathrm{BrdU}^{+}$cells in the SVZ of Tlx-OE mice by IHC analysis (Fig. 2F). Interestingly, the NSC number was correlated with Tlx copy number, which provides strong evidence that Tlx controls NSC number in vivo. To prove that the LRCs are indeed NSCs in vivo, we performed Tlx/GFAP/BrdU triple staining on those sections obtained from Tlx-OE mice. We found that most of the LRCs are Tlx/GFAP double positive, which indicates that they are B cells (Supplemental Fig. 4A). We did not see Tlx-negative cells, but GFAP/BrdU-positive cells, indicating that these cells are not nonneurogenic astrocytes. They are negative for DCX and NeuN, suggesting that they are neither immature nor mature neurons (Supplemental Fig. 4B,C). To confirm the results by an independent method, we performed the neurosphere assay, which has been suggested to reflect NSC number in vitro (Reynolds and Weiss 1992). In line with the in vivo data, we found a significant increase in the primary neurosphere frequency in Tlx-OE mice (Fig. 2G). We also found more neurospheres formed from single dissociated Tlx$\mathrm{OE}$ neurospheres, suggesting an increased self-renewal ability in vitro (Fig. 2H). Interestingly, the size of neurospheres from Tlx-OE mice was bigger as compared with those from wild-type mice (Fig. 2I,J). The percentage of Tlx-expressing cells $(15.2 \% \pm 4.3 \%)$ among individual neurospheres in the Tlx-OE mice was higher than in the control mice $(6.4 \% \pm 3.2 \%)$ (Fig. $2 \mathrm{~K})$, which suggests an increase in NSC number in the single neurosphere caused by Tlx overexpression. The low percentage of Tlxexpressing cells in the neurosphere reflects the very heterogeneous nature of neurospheres. Thus, based on the above results, we conclude that Tlx controls NSC number in vivo and in vitro by promoting self-renewal of NSCs, thereby underscoring the importance of Tlx for NSC biology in the adult SVZ, which we described previously (Liu et al. 2008).

Tlx represses transcription of target genes by binding to promoter sequences containing the binding site of $\mathrm{Tlx} / \mathrm{Yu}$ et al. 1994; CL Zhang et al. 2006). We showed that loss of Tlx leads to up-regulation of Pten, one of the Tlx target genes (Liu et al. 2008). Recently, another study suggested p21, a cyclin-dependent kinase inhibitor, as a target gene of Tlx (Sun et al. 2007). To investigate further the molecular pathways that contribute to the Tlx-OE phenotype, we performed real-time PCR-based gene expression analysis by using the SVZ obtained with laser-captured microdissection (Fig. 2L). We found that epidermal growth factor receptor (EGFR), PDGFR $\alpha$, Hes1, GPR56, Bmil, and cyclin D2 (Ccnd2) are up-regulated in the Tlx-OE mice, but PTEN, p21, p57, and Prox1 are down-regulated. 
Liu et al.
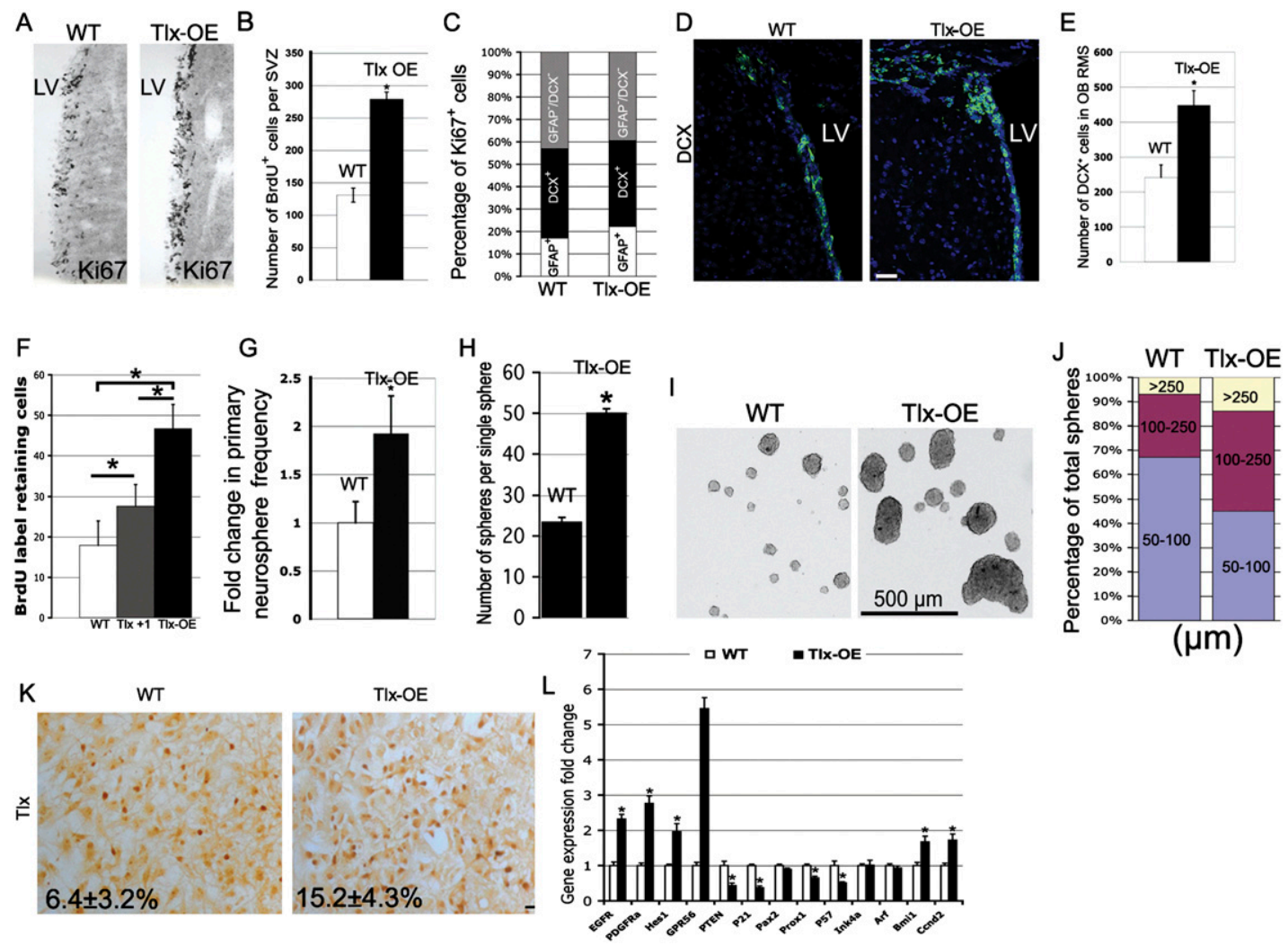

Figure 2. Tlx overexpression leads to expansion of NSCs in vivo and in vitro. (A) Coronal brain sections of the SVZ were stained with a Ki67 antibody. Note that there are more Ki67-positive cells in the SVZ of Tlx-OE mice as compared with wild-type (WT) mice. Tlx-OE mice in this and all other figures refer to the Tlx +2 copy line. $(B)$ Mice were sacrificed $2 \mathrm{~h}$ after BrdU injection, and 50- $\mu \mathrm{m}$ coronal sections were chosen for BrdU staining. BrdU-positive cells were counted and the results are shown as number of BrdU-positive cells per SVZ per section $(n=5, P<0.01$, mean \pm standard deviation [SD]). (C) Confocal optical sections of coronal sections of the mouse SVZ immunostained for GFAP together with Ki67 or DCX and Ki67. Numbers of double-positive cells were counted and are presented as percentage of total Ki67-positive cells (five sections were used from each mouse, $n=3)$. (D) Confocal optical sections of coronal sections of the mouse SVZ immunostained for DCX. Note that more DCX-positive cells were found in the SVZ of Tlx-OE mice. $(E)$ DCXpositive cells were counted in the RMS of the OB. Note a significant increase of DCX-positive cells in Tlx-OE mice $(n=4, P<0.01$, mean \pm standard deviation [SD]). (F) Number of BrdU LRCs in the adult SVZ. Mice received BrdU continuously in the drinking water for $1 \mathrm{wk}$, followed by a 3-wk survival period. Fifty-micron coronal sections were stained with BrdU, and BrdU-positive cells were counted as described above $(n=4, P<0.05$, mean \pm standard deviation [SD]). $(G)$ Fold change of primary neurosphere frequency. Neurosphere cultures were prepared as described in the Materials and Methods, and the number of primary neurospheres was determined $(n=3, P<0.05$, mean \pm standard deviation [SD]). $(H)$ Indvidual primary neurospheres were dissociated and plated into neurosphere culture medium (one sphere per well), and the number of secondary neurospheres were counted and are presented as number of spheres per single sphere $(n=3, P<0.05$, mean \pm standard deviation [SD]). (I) The size of primary neurospheres derived from the SVZ of Tlx-OE mice is bigger than in wild-type (WT) mice. (J) Percentage of neurospheres with different sizes among the total number of neurospheres. Neurospheres were categorized according to their diameter, and the percentage of different categories $(50-100$ $\mu \mathrm{m}, 100-250 \mu \mathrm{m}$, and $>250 \mu \mathrm{m}$ ) among the total populations was quantified (at least 200 neurospheres were measured for each mouse, $n=3)$. $(K)$ Tlx antibody staining of neurospheres. Note that more Tlx-expressing cells are found in neuropheres derived from Tlx-OE mice $(n=3, P<0.05$, mean \pm standard deviation [SD]). $(L)$ Quantitative PCR analysis of EGFR, PDGFR $\alpha$, HES1, GPR56, PTEN, p21 (Waf1), Pax2, Prox1, P57, Ink4a, Arf, Bmi1, and Ccnd2 mRNA expression in microdissected SVZ cells of the adult SVZ of wild-type and Tlx-OE mice $(n=5, P<0.05$, mean \pm standard deviation [SD]).

We did not observe any changes with Pax2, Ink4a, and Arf expression, indicating that Tlx does not interfere with these genes in the adult SVZ (more discussions are in the Supplemental Material).

\section{Tlx overexpression-induced NSC expansion persists in aging animals}

An important issue in adult stem cell biology is the balance between proliferation and self-renewal. Several genetic models have suggested that increased proliferation results in stem cell exhaustion (Kippin et al. 2005; Orford and Scadden 2008). To investigate whether Tlx overexpression-induced NSC expansion persists through life, we analyzed neurogenesis in the SVZ in Tlx-OE and littermate control mice during the aging process. Fourmonth-old, 17-mo-old, and 24-mo-old mice were chosen for the experiment, and Ki67 and DCX staining was performed and analyzed. Seventeen-month-old and 24-moold Tlx-OE mice consistently showed higher proliferation 
than wild-type mice (Fig. 3A). Interestingly, DCX staining indicated that neuroblasts were migrating into the striatum in 17-mo-old Tlx-OE mice, that the number of misplaced DCX-positive cells increased dramatically in 24mo-old Tlx-OE mice, and that misplaced DCX-positive cells were not found in wild-type mice (Fig. 3B). The distribution of Ki67-positive cells in the striatum of 24-mo-old Tlx mice suggested that these cells were also
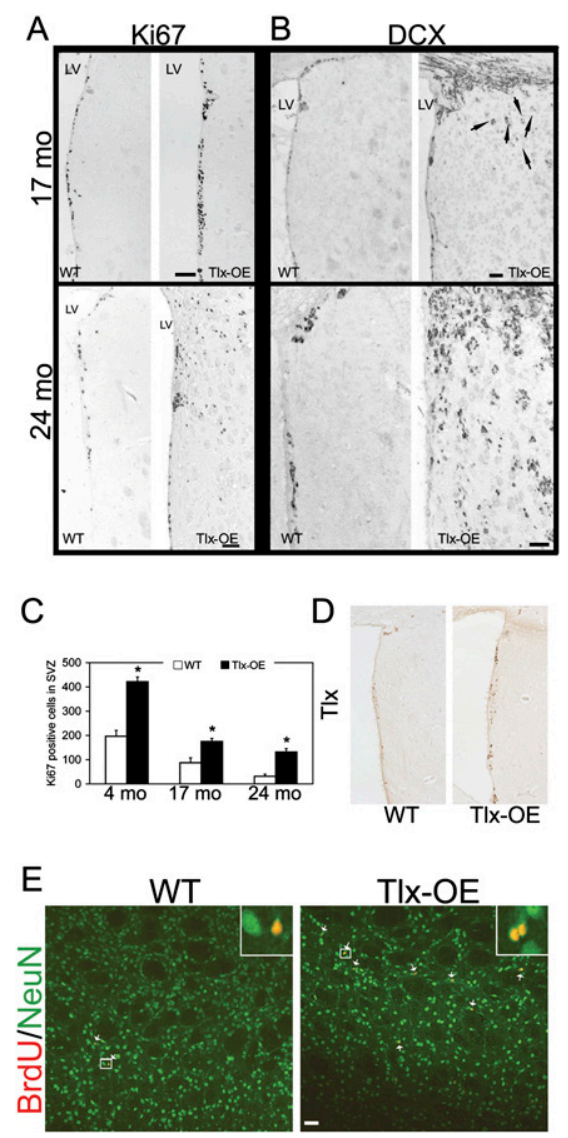

Figure 3. Tlx overexpression-induced NSC expansion is not a transient effect. $(A)$ Coronal sections from aged animals as indicated stained with Ki67. Note Ki67-positive cells outside of the SVZ in 2-yr-old Tlx-OE mice but not in wild-type mice, and in transgenic animals at the age of $17 \mathrm{mo}$. Bar, $100 \mu \mathrm{m} .(B)$ Coronal sections from aged animals as indicated stained with DCX. Note that more DCX-positive cells migrate out of the SVZ in the aged Tlx-OE mice, and more DCX-positive cells are found in the 2-yr-old Tlx-OE mice compared with 17-mo-old Tlx-OE mice (arrows). Bar, $50 \mu \mathrm{m}$. (C) Changes of Ki67-positive cells in the SVZ during aging. Note a decrease of cell proliferation in the SVZ of both wild-type and Tlx-OE mice. However, the number of Ki67-positive cells is significantly higher in Tlx-OE mice in all age groups $(n=3, P<0.05$, mean \pm standard deviation [SD]), with aged Tlx-OE mice showing Ki67 indices comparable with those of young wild-type mice. $(D)$ Tlx staining of 24-mo-old SVZ of wild-type and Tlx-OE brains. Note that more Tlx-expressing cells are present in the Tlx-OE SVZ. (E) BrdU feeding experiment was performed on 24-mo-old animals, and mice were analyzed for BrdU and NeuN costaining 7 wk after withdrawal of BrdU. Bar, $20 \mu \mathrm{m}$. proliferating (Fig. 3A). Quantification of the proliferation data demonstrated that the increased proliferation in the SVZ of Tlx-OE mice persists during aging; however, not at the same rate as compared with young mice (Fig. 3C). The decrease in proliferation rate in Tlx-OE mice from $17 \mathrm{mo}$ to 24 mo was lower than in wild-type mice (Fig. 3C). We therefore analyzed expression of Tlx in the 24-mo-old mice. Only a few cells express Tlx in the SVZ of wild-type mice, and more Tlx-positive cells were found in the TlxOE SVZ (Fig. 3D), which suggests that there are more stem cells. Taken together, these results demonstrate that Tlx-OE NSCs do not get exhausted as easily during aging in Tlx-OE as compared with wild-type mice.

To investigate whether the ectopic progenitors contribute to new neurons in the striatum, a BrdU feeding experiment was performed on 24-mo-old animals, and mice were analyzed for BrdU and NeuN costaining 7 wk after withdrawal of BrdU-containing water. Newborn neurons were rarely seen in age-matched wild-type mice (Fig. 3E, arrows). In contrast, many newborn neurons were found in Tlx-OE mice, suggesting that the ectopically distributed progenitors differentiated into mature neurons (Fig. 3E, arrows).

Tlx overexpression leads to spontaneous development of glioma-like lesions and gliomas

Tlx overexpression leads to an increased number of adult NSCs, which, together with the observed overexpression of the gene in brain tumors (Taylor et al. 2005; Modena et al. 2006; Phillips et al. 2006; Sim et al. 2006; Sharma et al. 2007), led us to analyze the consequences of $\mathrm{Tlx}$ overexpression in these mice. Brains from young Tlx-OE mice did not show any tumor-like lesions, but some aged mice $(>9 \mathrm{mo}$ ) developed tumor-like lesions arising out of the SVZ (five of 14 mice showed such lesions). The lesions demonstrate a higher cell density than normal brain tissue (Fig. 4A, arrows), and the cells within the lesions express the type A cell marker DCX, suggesting that these cells have a high migratory ability. These precursor lesions express GFAP (Fig. 4B), a stem cell marker in the SVZ that is also expressed in normal and reactive astrocytes as well as in glioma cells. The lesions are highly proliferating, as shown by Ki67 and DCX coexpression (Fig. 4C). In the striatum of Tlx-OE mice, we found small clusters of cells that are DCX-positive (Fig. 4A, arrows) and had migrated out of the SVZ into the striatum. The lesions showed some of the characteristics of infiltrative gliomas, with cells migrating along white matter tracts (Fig. 4D, arrows) and forming satellitosis-like perineuronal structures (Fig. 4E, arrow). We also performed NG2 and PDGF $\alpha$ staining of the lesions costained with DCX, which are present in some stem/progenitors of the SVZ$\mathrm{OB}$ neurogenic lineage. Some of the cells in the lesions express those two markers, although they are not coexpressed with DCX (Supplemental Fig. S5). Some of the lesions progress into astrocytomas in $>2$-yr-old mice (Fig. $4 \mathrm{~F}, \mathrm{G})$. In our model, the effect of the genetic alteration occurs only in astrocyte-like B cells, suggesting that the glioma-like lesions arise directly from Tlx-OE NSCs. 
Liu et al.

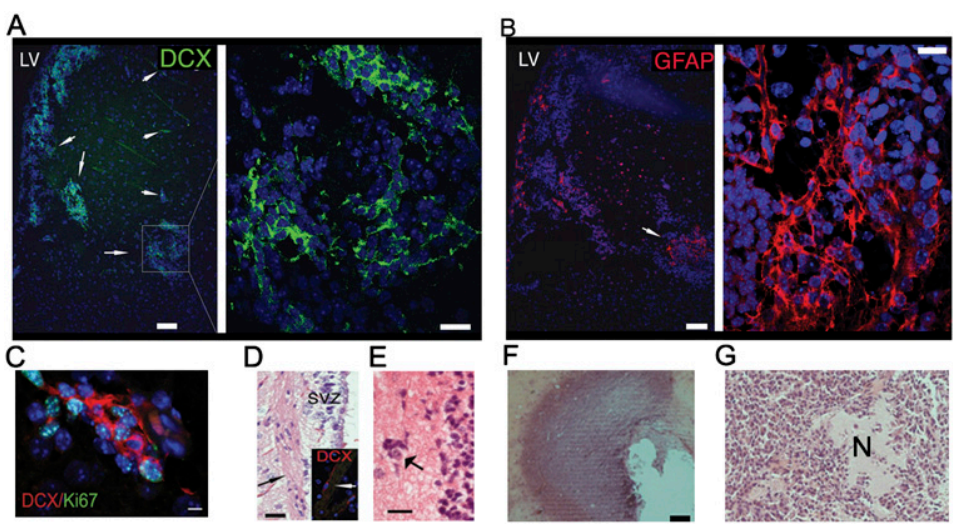

Figure 4. Tlx-OE mice spontaneously develop gliomalike lesions and gliomas. (A) Confocal optical sections of coronal sections of 9-mo-old Tlx-OE mice stained with DCX. Note that DCX-expressing cells migrate out of the SVZ and form glioma-like lesions with a high cell density (arrows). (B) Confocal optical sections of coronal sections of 9-mo-old Tlx-OE mice stained with GFAP. Note that the cellular lesion in the striatum is strongly GFAP-positive (arrow). (C) Confocal optical sections of coronal sections of 9-moold Tlx-OE mice stained with DCX (red) and Ki67 (green). Note that the double-positive cells are highly proliferating and migrating. Bar, $10 \mu \mathrm{m}$. $(D)$ H\&Estained Tlx-OE brain coronal sections and DCXstained (inset, red) Tlx-OE brain coronal sections. Note that the migrating cells are associated with white matter tracts (arrows). (E) H\&E staining. Arrow indicates a satellitosis-like perineuronal structure around the lesion. $(F, G) \mathrm{H} \& \mathrm{E}$ staining of gliomas from some 2-yr-old Tlx-OE mice. (N) Necrosis.

However, the majority of the Tlx-OE mice do not develop macroscopic gliomas in the period analyzed, possibly reflecting that multiple mutations are required for the induction and progression of brain tumors in vivo (Holland et al. 1998).

\section{Overexpression of Tlx leads to glioma formation upon loss of p53}

Mutation of the tumor suppressor gene p53 is a frequent event in human gliomas, in particular in diffuse astrocytic gliomas, including glioblastomas (Louis 1994). The Cancer Genome Atlas data demonstrate that p53 mutation is a very common event in human glioblastomas (The Cancer Genome Atlas Research Network 2008). The genetic inactivation of p53 in mice itself does not lead to spontaneous glioma formation (Donehower et al. 1992; Jacks et al. 1994). However, loss of p53 in combination with other genetic modifications has been used to generate mouse glioma models (Fomchenko and Holland 2006). Although a recent study suggests that $\mathrm{p} 53$ deletion via a human GFAP promoter-driven Cre recombinase leads to brain tumor formation (Wang et al. 2009), we did not find any brain tumors in our littermate $\mathrm{p} 53^{-/-}$mice. Anticipating that loss of p53 in combination with Tlx overexpression will lead to earlier brain tumor formation, Tlx-OE mice were bred into the $\mathrm{p} 53^{-/-}$background, and Tlx-OE; $553^{-/-}$mice were analyzed with littermate $\mathrm{p} 53^{-/-}$ as controls. In addition, we did not find any brain tumor formation in mice that have an adult NSC-specific inactivation of p53 (H-K Liu and G Schütz, unpubl.).

To investigate the effect of p53 loss in NSCs of the SVZ of Tlx-OE mice, we analyzed the proliferation of SVZ cells and found a higher fraction of $\mathrm{Ki} 67^{+}$cells in the SVZ of 8-wk-old Tlx-OE;p53 $3^{-1-}$ mice as compared with wildtype and Tlx-OE mice. Interestingly, some Ki67 $7^{+}$cells in the Tlx-OE;p53 ${ }^{-1-}$ mice had migrated out of the SVZ into the striatum (Fig. 5A, arrows). This phenotype was confirmed by BrdU incorporation experiments (Fig. 5B, arrows). In contrast, $\mathrm{p} 53^{-/-}$mice did not show migration of proliferating cells out of the SVZ, which is consistent with a previous report (Gil-Perotin et al. 2006). To in- vestigate the identity of these migratory cells, we performed Ki67 and DCX double staining and found that a large number of DCX-expressing cells also expressed Ki67 outside of the SVZ in the Tlx-OE; $553^{-1-}$ mouse brain (Fig. 5C, arrows). Interestingly, hyperproliferative lesions characterized by increased cellular density and higher expression of Ki67 were found frequently in Tlx-

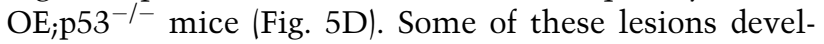
oped into small tumors, and the tumor cells became invasive during further progression, as indicated by IHC analysis (Fig. 5E).

Some 2-mo-old Tlx-OE;p53 ${ }^{-1-}$ mice already developed gliomas (Fig. 5E, panel a), with cells at the border of tumors invading the neighboring regions (Fig. 5E, panel a, arrows; Supplemental Fig. S6A,B, arrows). All Tlx$\mathrm{OE}_{j} \mathrm{p} 53^{-/-}$mice older than 5 mo carried glioma lesions $(n=16)$, with nine animals demonstrating multifocal manifestations. The tumors are mostly WHO grade I-III astrocytomas. Some tumors obtained from 7-mo-old mice developed features of high-grade astrocytomas; for example, nuclear atypia (Supplemental Fig. S6C, arrows) and pseudopalisading necrosis (Supplemental Fig. S6D). These findings suggest that development of grade IV brain tumors may need a longer time period until cells acquire additional genetic alterations. Some of the tumors accumulated cells at the pial surface of the cortex (Fig. 5E, panel b). The tumors were composed of relatively small, partially GFAP-positive cells with a high Ki67 labeling index (Fig. 5E, panels c,d). The invasive tumor cells at the tumor border are highly proliferating, as indicated by Ki67 staining (Fig. 5E, panel e). Only a minor subpopulation of the tumor cells expressed Tlx (Fig. 5E, panel f), in line with the low percentage of BTSCs in brain tumors. Expression of the neuronal marker $\mathrm{NeuN}$ in the tumor tissue was restricted to individual entrapped neurons, while the tumor cells were NeuN-negative (Fig. 5E, panel g, arrows). In the infiltration zone, tumor cells formed perineuronal satellitoses around resident NeuN-positive neurons (Fig. 5E, panel h, arrows). Mash1, a neural progenitor marker, is also expressed by Tlxinduced tumors, and there are more Mash1-positive cells than Tlx-positive cells, suggesting an enriched progenitor 


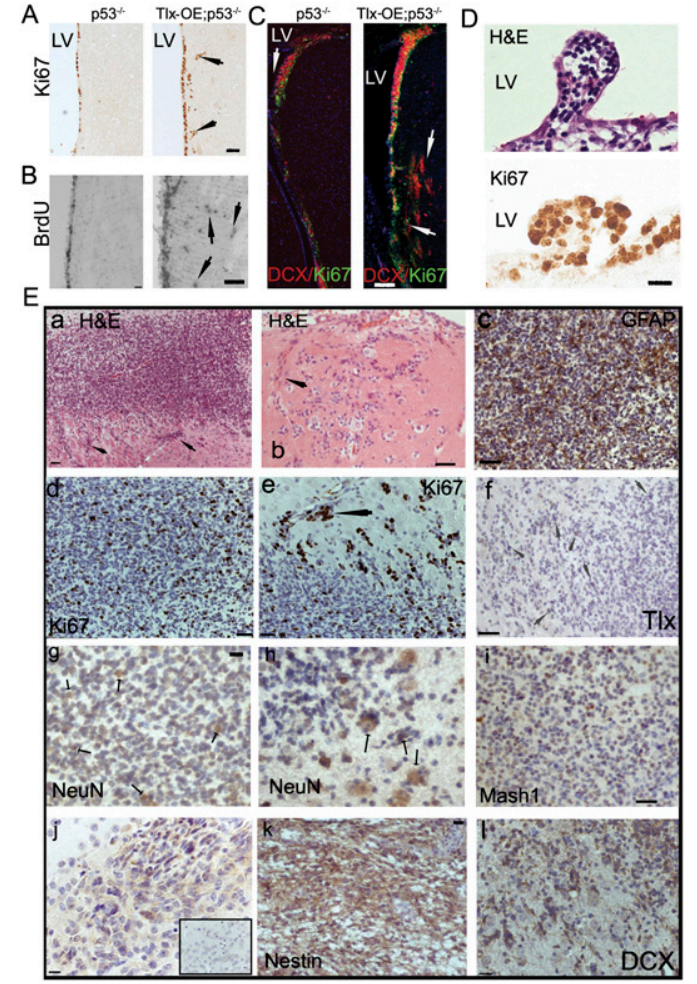

Figure 5. Brain tumor development from SVZ of Tlx-OE mice upon loss of p53. (A) Two-month-old mice were injected with BrdU $2 \mathrm{~h}$ before sacrifice, and coronal sections were stained with Ki67. Note Ki67-positive cells outside of the SVZ in Tlx-OE;p53 ${ }^{-1-}$ mice (arrows). (B) Two-month-old mice were injected with BrdU $2 \mathrm{~h}$ before sacrifice, and coronal sections were stained with BrdU. Arrows indicate BrdU-positive cells in the striatum of TlxOE; $53^{-1-}$ mice. $(C)$ Two-month-old mice were injected with BrdU $2 \mathrm{~h}$ before sacrifice, and coronal sections were stained with DCX (red) and Ki67 (green). Note that $\mathrm{p} 53^{-/-}$mice do not show migration of the SVZ proliferating cells toward the striatum in comparison with Tlx-OE;p53-l- mice (arrows). (D) Threemonth-old Tlx-OE;p53 ${ }^{-/-}$mice develop hyperproliferative lesions as indicated by $\mathrm{H} \& \mathrm{E}$ and Ki67 staining. (E) Tlx-OE;p53 ${ }^{-/-}$mice spontaneously develop gliomas. (Panel a) Tumor sections stained with $H \& E$. Note a highly cellular, small cell glioma with diffuse infiltration of the adjacent brain. Arrows indicate tumor cell clusters migrating to neighboring regions. Bar, $100 \mu \mathrm{m}$. (Panel $b$ ) Tumor sections stained with H\&E. Accumulation of tumor cell clusters in the subpial zone of the cortex (arrow). Bar, $50 \mu \mathrm{m}$. (Panel c) Strong expression of GFAP in tumors. Bar, $50 \mu \mathrm{m}$. (Panel d) The tumor cells are highly proliferative, as indicated by Ki67 staining. The proliferation index of the depicted tumor was $\sim 15 \%$, with a higher density of Ki67-positive cells at the tumor periphery. Bar, $50 \mu \mathrm{m}$. (Panel e) More proliferating cells are located at the border of the tumor (arrow). Bar, $50 \mu \mathrm{m}$. (Panel $f$ ) Tumor sections stained with the Tlx antibody. Arrows indicate Tlx-positive cells. Bar, $50 \mu \mathrm{m}$. (Panel $\mathrm{g}$ ) Interspersed NeuNpositive neurons in the tumor tissue (arrows). Bar, $50 \mu \mathrm{m}$. (Panel h) Perineuronal satellitosis characterized by tumor cells surrounding $\mathrm{NeuN}^{+}$neurons (arrows). (Panel i) Mash1 immunoreactivity in Tlx-induced tumors. Bar, $15 \mu \mathrm{m}$. (Panel $j$ ) Some tumor cells are P-Akt-positive, indicating an alteration of the Pten/Pi3k/Akt pathway; the inset indicates a tumor-free striatal region. (Panel k) Nestin is highly expressed by Tlx overexpression-induced gliomas. (1) DCX is strongly expressed by infiltrating tumor cells. population in the tumors (Fig. 5E, panel i). Immunohistochemistry revealed increased P-Akt staining in the tumors, suggesting aberrant activation of the Pten/Pi3k/Akt pathway (Fig. 5E, panel j), consistent with Tlx being a repressor of PTEN gene transcription. The Tlx-induced tumors were strongly positive for nestin (Fig. 5E, panel k), suggesting a high percentage of tumor cells with progenitor cell-like phenotypes. At the border of tumors, DCX was highly expressed, reflecting the invasive properties of these cells (Fig. 5E, panel 1).

\section{Angiogenesis-mediated stem cell invasion may lead to the multifocal pathology of tumors}

The initiation of gliomas in Tlx-OE;p53-1- mice suggests that Tlx is a crucial regulator of brain tumor initiation from NSCs of the adult SVZ. Only limited regions contain NSCs in the adult mammalian brain. Gliomas have the very characteristic feature that they are highly invasive, displaying an infiltrative growth pattern (Scherer 1940). Notably, SVZ cells in our mouse model show strong migratory ability, as indicated by DCX- and Ki67-expressing cells outside of the SVZ. DCX has been suggested to be expressed preferentially by invasive glioma cells (Daou et al. 2005). A detailed histological analysis showed the infiltrative growth of tumor cells out of the SVZ (Fig. 6A, arrows). These invasive cells were proliferating, as reflected by Ki67 expression (Fig. 6B), and were frequently associated with vessels, as indicated by their spatial proximity to endothelia (Fig. 6B, inset, arrow). DCX was expressed strongly in these cells, in line with their migratory activity (Fig. 6C). We also found some Tlx-positive but DCX-negative cells around the lesion (Fig. 6D, arrows), indicating that Tlx-positive stem cells possibly migrate away from the SVZ under certain conditions.

It was demonstrated that BTSCs are also located in a perivascular niche (Calabrese et al. 2007) and induce angiogenesis via activating VEGF signaling (Bao et al. 2006b). The association of tumor lesions with blood vessels suggests that the angiogenic pathway is involved in this process. As a major regulator for angiogenesis, VEGFR2 has been implicated in adult SVZ neurogenesis (Jin et al. 2002). It has been shown that Tlx regulates the angiogenic process during retinal development, and the expression of VEGFR2 is strongly down-regulated in the $\mathrm{Tlx}^{-/-}$retina (Uemura et al. 2006). In line with these observations, we found that the expression of VEGFR2 is up-regulated in the SVZ of Tlx-OE mice (Fig. 6E). To better illustrate the distribution of Tlx-expressing cells in the adult SVZ, CD31, an endothelial marker, was used for costaining with Tlx. We found that Tlx-expressing cells are distributed preferentially in the vascular niche, and we frequently found more vascular structures in the SVZ of Tlx-OE mice (Fig. 6F). Additional analysis of the distance between Tlx-expressing cells and vessels indicates that most of the Tlx-expressing cells are distributed close to the vascular niche in the wild-type SVZ (Fig. 6G), which is consistent with previous reports (Ninkovic and Gotz 2007; Shen et al. 2008; Tavazoie et al. 2008). We 

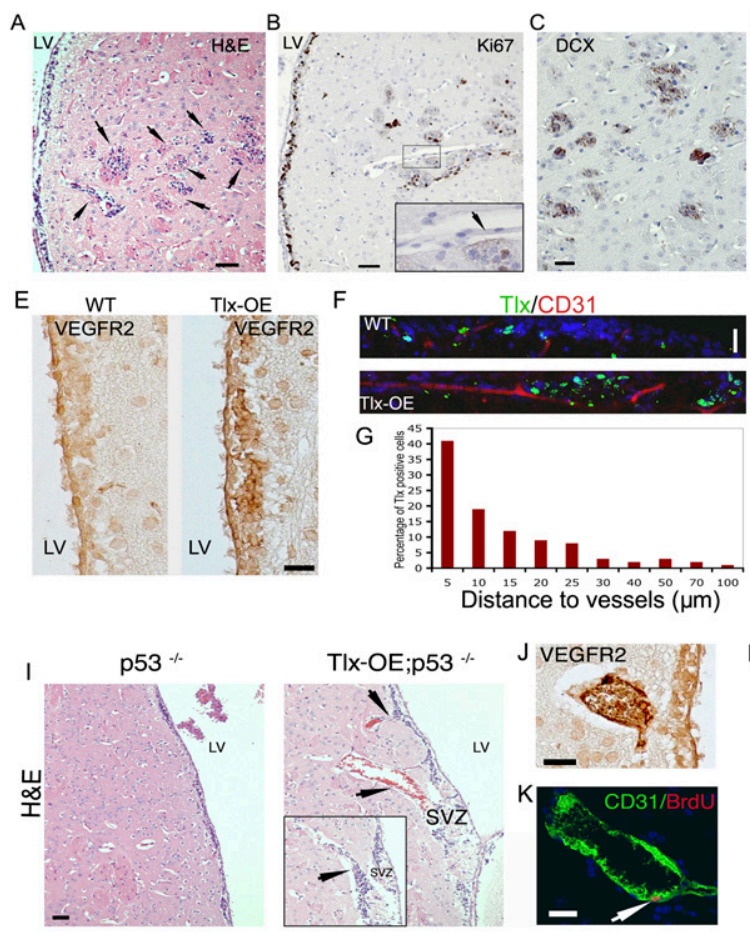

$\mathrm{L}$
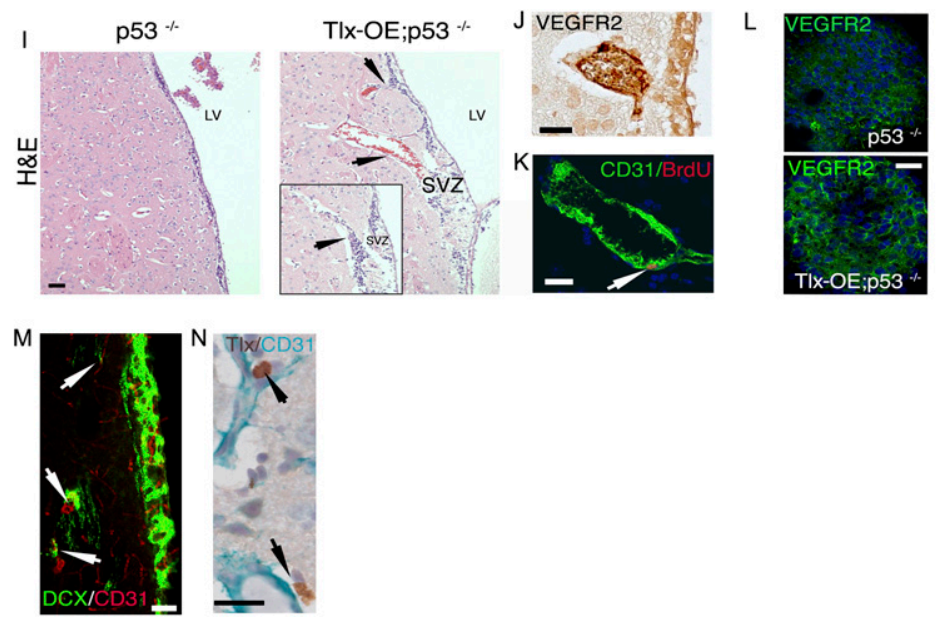

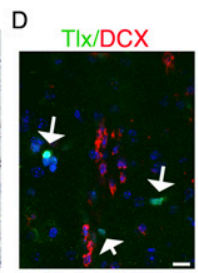

$\mathrm{H}$

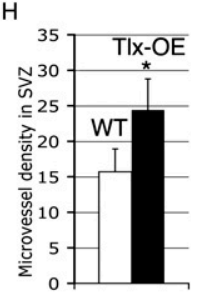

Figure 6. Tlx overexpression leads to increased angiogenesis and subsequent neural progenitor cell (NPC) invasion. (A) H\&E staining of brain sections from Tlx$\mathrm{OE} ; \mathrm{p} 53^{-1-}$ mice. Arrows indicate multifocal glioma-like lesions with high cell density. Bar, $50 \mu \mathrm{m}$. (B) Adjacent sections from $A$ were stained with Ki67. (Inset) Note that the multifocal lesions are Ki67-positive, and that an endothelial-like structure is associated with the lesions (arrow). Bar, $50 \mu \mathrm{m}$. (C) Adjacent sections from $A$ were stained with DCX. Note that the lesions are DCXpositive, indicating a highly invasive nature. $(D)$ Brain sections from Tlx-OE mice that contain glioma-like lesions were stained with Tlx (green) and DCX (red). Note that there are Tlx-expressing isolated cells around the lesion, but they are negative for DCX. (E) Brain sections from wild-type and Tlx-OE mice were stained for VEGFR2. Note that Tlx-OE mice display higher expression of VEGFR2 in the SVZ. (F) Tlx (green) and CD31 (red) staining demonstrates that Tlx-expressing cells are located in a vascular niche in wild-type and TlxOE SVZ. $(G)$ Tlx-positive cells are located preferentially in the vascular niche in the wild-type SVZ. The distance between Tlx-expressing cells and the closest vessel was measured, and is presented as percentage of positive cells at different distances to vessels (>1000 Tlx-positive cells were analyzed). (H) Numbers of vessels in the SVZ of wild-type and Tlx-OE mice. Note that only the vessels that are CD31-positive and longer than $50 \mu \mathrm{m}$ were counted $(n=5, P<0.05$, mean \pm standard deviation [SD]). (I) Histological analyses indicate more blood vessels close to the SVZ of Tlx-OE; $553^{-1-}$ mice compared with $\mathrm{p} 53^{-1-}$ mice (arrows). (Inset) An adjacent section demonstrates that SVZ cells of the Tlx-OE;p53-1- mice accumulate at the surface of a vessel (arrow). Bar, $50 \mu \mathrm{m}$. $(J)$ The top vessel in $I$ (arrow) is highly VEGFR2-positive. $(K)$ The bottom vessel in $I$ is proliferating as indicated by CD31 and BrdU staining. BrdU was injected $2 \mathrm{~h}$ before sacrifice. $(L)$ Primary neurospheres derived from the SVZ of Tlx-OE;p53 $3^{-1-}$ and $\mathrm{p} 53^{-1-}$ mice were stained with VEGFR2. Note the
higher intensity of VEGFR2 staining in Tlx-OE;p53 $53^{-/-}$neurospheres. $(M)$ DCX and CD31 staining demonstrates the migration of neural progenitor cells along blood vessels (arrows). (N) Sections from the border of the gliomas from Tlx-OE; $53^{-1-}$ mice were stained with Tlx and CD31. Note that Tlx-positive cells are also located in a perivascular niche (arrows).

further measured microvessel density in the Tlx-OE SVZ, and more vessels were found compared with the wildtype SVZ (Fig. 6H). Further analyses demonstrate that a higher density of blood vessels was also detectable close to the SVZ in the Tlx-OE; $553^{-1-}$ mouse brain (Fig. 6I). The SVZ cells migrated toward and along the vessels (Fig. 6I, inset, arrows). The vessels were also highly VEGFR2positive (Fig. 6J). Using CD31 and costaining for BrdU, we obtained direct proof of in vivo angiogenesis (Fig. 6K, arrow). This alteration was not found in the SVZ of wildtype mice, which is consistent with previous studies (Shen et al. 2008; Tavazoie et al. 2008). Increased VEGFR2 expression was confirmed in neurospheres derived from Tlx-OE; $553^{-/-}$mice and $\mathrm{p} 53^{-/-}$mice (Fig. 6L). DCX and CD31 costaining indicates association of the migrating cells with blood vessels (Fig. 6M, arrows). It has been reported that the BTSCs are located in a perivascular niche (Calabrese et al. 2007). Interestingly, we observed by Tlx and CD31 staining that Tlx-expressing cells at the border of the tumors were also located in a perivascular niche (Fig. 6N, arrows). In conclusion, our results strongly indicate that brain tumor-initiating cells leave the SVZ and generate a new niche for their maintenance and growth in vivo.

\section{Tlx expression in human gliomas}

We demonstrated above in a mouse model that Tlx is a crucial regulator for glioma initiation. Several recent studies reported that Tlx is overexpressed in subsets of human brain tumors (Taylor et al. 2005; Modena et al. 2006; Phillips et al. 2006; Sim et al. 2006; Sharma et al. 2007). Expression of NR2E1 (Tlx) assessed in a set of 63 malignant astrocytomas by oligonucleotide hybridization revealed an elevated level of hybridization in a subset of tumors compared with normal brains (Fig. 7A). In particular, in nine of 41 primary glioblastomas, expression was increased. The same set of tumors was analyzed by array comparative genomic hybridization (arrayCGH) for genome-wide DNA copy number alterations. Two of the nine glioblastomas with elevated NR2E1 mRNA levels showed gains in the NR2E1 gene copy number, one of 

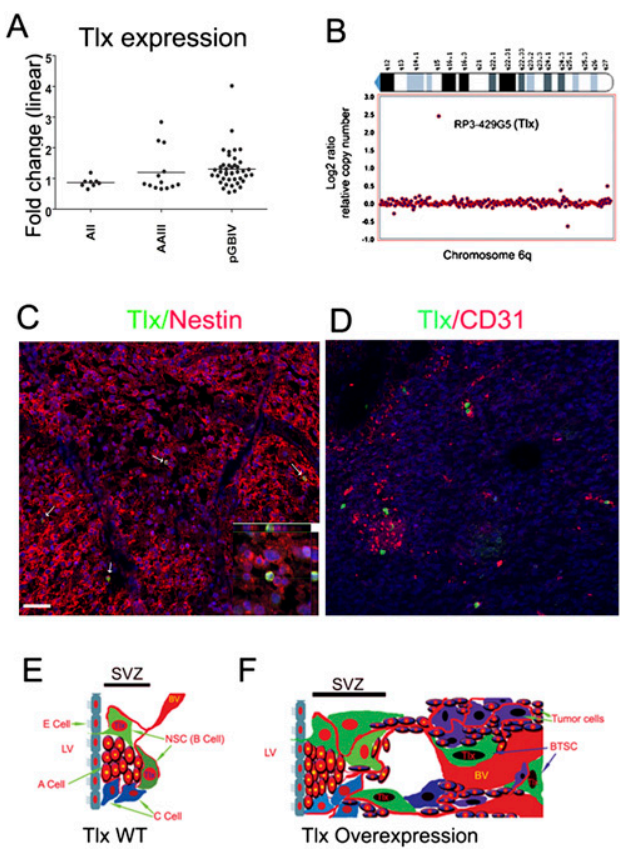

Figure 7. Expression of $\mathrm{Tlx}$ in human gliomas. (A) Elevated expression of NR2E1 (Tlx) in human gliomas. Box plot representing the expression of NR2E1 in three glioma entities when compared with a normal brain. Data were obtained for diffuse astrocytoma (AII, $n=8$ ), anaplastic astrocytoma (AAIII, $n=14$ ), and primary glioblastoma (pGBM, $n=41$ ). The fold change factor is calculated from comparisons with the expression data of eight normal brains simultaneously analyzed. Note that nine of 41 primary glioblastomas show significant overexpression of NR2E1. $(B)$ NR2E1 amplification from one of two human glioblastoma cases. ArrayCGH was performed with the same set of tumors described in $A$. Two cases have genomic amplification of NR2E1. Note that these two cases are from the nine cases that showed increased expression of Tlx from $A .(C)$ Human glioblastoma sections were costained for Tlx (green) and nestin (red). Note that only a subpopulation $(11.2 \% \pm 4.3 \%$, $n=5$ ) of nestin-positive cells express Tlx. (D) Human glioblastoma sections were costained with Tlx (green) and CD31 (red). Note that Tlx-positive cells are located in a perivascular niche. (E) Cellular composition of the adult SVZ in wild-type mice comprising the astrocyte-like B cells, the transient amplifying type C cells, and the migrating type A cells. Note that Tlx is expressed exclusively by astrocyte-like B cells in the adult SVZ, and that a vascular niche is involved in the maintenance of the stem cell population. (BV) Blood vessel; (E) ependymal; (LV) lateral ventricle. $(F)$ Tlx overexpression induces an increase of neural stem/progenitor cells and, as a consequence, the SVZ cell populations expand. In parallel, angiogenesis is stimulated by overexpression of Tlx. The neural stem/progenitor cells migrate along the vessels and invade neighboring regions. Tlx-positive glioma-initiating cells (BTSCs) are located in a perivascular niche and induce tumor formation.

which was a high-level copy number gain of a confined region containing NR2E1 (Fig. 7B). Elevated expression of NR2E1 in comparison with a reference pool of cell lines was also reported recently in the data set on glioblastoma from the Cancer Genome Atlas Consortium (see http:// tcga.cancer.gov/dataportal/data/about).
We showed that Tlx is expressed exclusively by the astrocyte-like stem cells in the adult mouse SVZ (Liu et al. 2008). Accordingly, immunostaining of human glioblastoma sections revealed that only a small population $(11.2 \% \pm 4.3 \%)$ of the nestin-positive cells coexpressed Tlx (Fig. 7C, arrows). A perivascular niche has been suggested to be important for the maintenance of BTSCs (Calabrese et al. 2007). We showed that Tlx stimulates angiogenesis to create a new niche for the maintenance of stem cells in our mouse model. Compatible with this conclusion, we found by Tlx and CD31 costaining that Tlx-expressing cells in glioblastomas are located in a perivascular niche (Fig. 7D; Supplemental Fig. S7C).

\section{Discussion}

\section{Tlx regulates NSC number in vivo and in vitro}

We reported previously that $\mathrm{Tlx}$ heterozygous mice exhibit less neurogenesis in the adult SVZ (Liu et al. 2008). Here we demonstrate that the number of LRCs-that is, the resident NSCs-is correlated with Tlx gene copy number. As a consequence, we find increased neurogenesis in the Tlx-OE adult SVZ-OB. We and others have shown that Tlx inhibits expression of Pten by binding to the promoter of the Pten gene $/ \mathrm{CL}$ Zhang et al. 2006; Liu et al. 2008). Pten has been reported to be a negative regulator of NSC self-renewal and proliferation in the fetal brain (Groszer et al. 2001, 2006). We demonstrate here that Pten is repressed by Tlx overexpression in NSCs, implying that Tlx promotes selfrenewal of NSCs by inhibiting the Pten/Pi3k/Akt pathway. However, loss of Pten function in adult NSCs does not lead to preneoplastic lesions (H-K Liu and G Schütz, unpubl.), which suggests that additional pathways are affected by Tlx overexpression.

It has been shown that the Notch signaling pathway regulates NSC number in vivo and in vitro (AndroutsellisTheotokis et al. 2006). Interestingly, we found that Hes 1, a key regulator in the Notch pathway, is up-regulated in Tlx-OE NSCs. Overexpression of Hes 1 and other components of the Notch patway have also been demonstrated in human glioblastomas (Phillips et al. 2006; Kanamori et al. 2007). Together, these observations suggest that Tlx is also involved in the regulation of Notch signaling in NSCs and brain tumors, although the detailed mechanisms need further investigation. In addition, we show that the expression of PDGFR $\alpha$ is altered by overexpression of Tlx. These receptors have been reported to be important for NSC regulation in the adult SVZ (Jin et al. 2002; Jackson et al. 2006; Jain et al. 2007). Interestingly, infusion of PDGF into the lateral ventricle leads to glioma-like lesions adjacent to the SVZ (Jackson et al. 2006).

Tlx is expressed by neurospheres that are widely used for studying NSCs in vitro. Overexpression of Tlx leads to production of more and larger neurospheres, with a higher fraction of Tlx-positive cells per neurosphere. These findings suggest that Tlx may be used as a stimulator 
for NSC expansion in vitro for the therapeutic use of NSC transplantation. Interestingly, the transcriptional factor Hoxb4 has a similar function in hematopoietic stem cells (HSCs); i.e., forced expression of Hoxb4 leads to the expansion of HSCs (Antonchuk et al. 2002). Taken together, our in vivo and in vitro data strongly implicate Tlx as a key regulator for the regulation of NSC number.

It has been suggested that increased proliferation of stem cells results in their exhaustion /Orford and Scadden 2008). For instance, loss of p21 leads to loss of neurosphere-initiating cells with aging (Kippin et al. 2005), and Pten-deficient adult HSCs show a transient increase but long-term depletion of proliferation (Yilmaz et al. 2006; J Zhang et al. 2006). It has also been shown that SVZ neurogenesis declines in aged animals (Maslov et al. 2004). Recently, it was demonstrated that loss of FOXOs, which are known to be important downstream players in the PTEN/Akt pathway, also leads to transient increase but long-term decrease of NSC proliferation (Paik et al. 2009; Renault et al. 2009). Interestingly, the higher proliferative activity within the SVZ of Tlx-OE mice persists in aged (2-yr-old) mice; i.e., the proliferation rate in aged Tlx-OE mice was similar to that of young wild-type mice (Fig. 3C). This finding suggests that overexpression of Tlx counteracts the pathways that are involved in the decline of NSCs. Interestingly, Ink4a expression is increased in SVZ NSCs during aging (Molofsky et al. 2006), and Ink4adeficient aged mice have more NSCs than wild-type mice, which is similar to what we found in the Tlx-OE aged animals. We did not observe changes in Ink4a or Arf in Tlx-OE SVZ cells, which suggests that Tlx does not function through the Ink4a pathway. PTEN and p21 are known to be target genes of Tlx (CL Zhang et al. 2006; Sun et al. 2007; Liu et al. 2008). Crossing Tlx-CreER ${ }^{\mathrm{T} 2}$ mice with mice containing the conditional allele of PTEN results in an adult NSC mutation of PTEN (Liu et al. 2008), which leads to PTEN inactivation in adult NSCs but does not lead to glioma formation. The tumor appears when p53, a major p21 transcriptional activator, is mutated in addition in adult NSCs (H-K Liu and G Schütz, unpubl.). This suggests that Tlx regulates NSC expansion and maintenance through the PTEN and p21 pathway. Interestingly, overexpression of tailless in the fly causes brain hyperplasia and generates supernumery neuroblasts (Kurusu et al. 2008), indicating that the control of neural progenitor proliferation by the tailless gene is conserved in Drosophila and mice.

\section{The origin of brain tumors}

The SVZ has been suggested as the site of origin of brain tumors (Smyth and Stern 1938; Globus and Kuhlenbeck 1942; Vick et al. 1977). This germinal zone has a unique niche for the maintenance of NSCs in the adult mammalian brain (Doetsch 2003). Recent advances in BTSCs research indicate similarities between BTSCs and NSCs; for example, the self-renewal ability and multipotency, the expression of nestin and CD133, and the ability to form spheres under certain culture conditions (Vescovi et al. 2006). Loss of the tumor suppressors p53 and NF1 in
GFAP-expressing cells leads to astrocytoma formation, and the tumors are frequently found close to the SVZ region in this mouse model (Zhu et al. 2005). An activated Akt and Ras double mutation introduced into nestinexpressing cells causes glioma formation, also suggesting that neural stem/progenitor cells are more sensitive to be transformed (Holland et al. 2000). However, the direct contribution of the SVZ NSCs to brain tumor formation has not been demonstrated due to the lack of specific promoters for NSCs.

The similarity between BTSCs and NSCs suggests that important regulators of NSCs may play a similar role in BTSCs. We showed previously that Tlx is expressed exclusively in resident NSCs in the adult mouse SVZ and that it is essential for their generation and maintenance (Liu et al. 2008). In this study, we show that overexpression of Tlx in NSCs leads to expansion of NSC number and gliomatous proliferative lesions in the aged mouse brain. These lesions appear much earlier upon p53 loss and then often progress to invasive gliomas. Since the BAC-based Tlx transgene is overexpressed exclusively in NSCs, this strongly indicates that these tumors arise directly from the Tlx-expressing NSCs. Further analysis demonstrates that the SVZ stem/progenitor cells migrate out of the SVZ along the white matter and/or blood vessels, which are the typical routes for migrating glioma cells. These results suggest that the diffusely infiltrative phenotype of gliomas and the sometimes multifocal manifestation may be caused by displacement of SVZ NSCs and their growth and expansion in an ectopic niche (Fig. 7E,F). Loss of p53 accelerates the development of Tlx-mediated brain tumors with early migration of NSCs out of their physiological niche; i.e., the SVZ. The mechanism behind this phenotype is not clear. However, p53 knockout mice do not show these changes, which strongly implies the importance of Tlx overexpression.

\section{Clinical implications}

We demonstrated that Tlx is a functionally important NSC marker by the loss-of-function approach (Liu et al. 2008). Here we show that overexpression of Tlx leads to expansion of NSCs and invasive glioma development in cooperation with loss of $\mathrm{p} 53$. These results, together with the results of Tlx expression in human brain tumors, provide strong evidence for the SVZ as a site for glioma initiation. Strikingly, we also found that some human glioblastomas contain genomic amplifications of the Tlx gene. We showed that Tlx is crucial for self-renewal and maintenance of adult NSCs, since loss of Tlx leads to complete loss of cell proliferation in the adult SVZ (Liu et al. 2008). Targeting of BTSCs is a major obstacle for glioma therapy, since these cells are supposed to be more resistant to current therapeutic approaches (Bao et al. 2006a). The similarity of BTSCs and NSCs suggest that they may use similar machinery for their maintenance. Specific expression of Tlx and the importance of this nuclear receptor for brain tumor initiation provide a unique advantage to precisely target Tlx-expressing cells, including 
BTSCs. This intriguing hypothesis can now be tested with our mouse model, which may allow the development of novel approaches toward targeted brain tumor therapy.

\section{Materials and methods}

\section{Animals}

Mice were housed according to international standard conditions, and all animal experiments conformed to local and international guidelines for the use of experimental animals. Generation of Tlx-OE mice was processed as described in the Supplemental Material.

The Tlx-null mutant was generated previously in the laboratory (Monaghan et al. 1997). p53-null mice were obtained from The Jackson Laboratory and were maintained in a C57Bl6/J background.

\section{Histological analysis and immunohistochemistry}

Mice were perfused with $4 \%$ paraformaldehyde (PFA) and brains were dissected, followed by overnight fixation in $4 \%$ PFA at $4{ }^{\circ} \mathrm{C}$. Paraffin-embedded brains were sectioned at $5 \mu \mathrm{m}$ and were stained with hematoxylin and eosin (H\&E). Stained sections were examined by light microscopy. For antibody staining, paraffin sections were deparaffinized and rehydrated, blocked in $5 \%$ normal swine serum in PBST (PBS $+0.2 \%$ Triton-X 100), and incubated overnight at $4^{\circ} \mathrm{C}$ with the primary antibody. Further information is included in the Supplemental Material.

\section{Neurosphere cultures}

Neurospheres were prepared from adult mouse SVZ (three mice per group) as described (Chojnacki and Weiss 2008), and the number of primary neurospheres was determined. The RNA from neurospheres was isolated by using the Cells-to-cDNA II Kit from Ambion.

\section{BrdU administration}

$\mathrm{BrdU}$ (Sigma) was dissolved in sterile $\mathrm{NaCl}$ to prepare the 15 $\mathrm{mg} / \mathrm{mL}$ solution, and mice were injected intraperitoneally with $50 \mathrm{mg} \mathrm{kg}^{-1} 2 \mathrm{~h}$ before sacrifice. For provision of BrdU by feeding, BrdU was dissolved in the drinking water to prepare a $1 \mathrm{mg} / \mathrm{mL}$ solution.

\section{RNA purification and real-time PCR}

The laser-captured microdissection of the SVZ and the RT-PCR for Tlx was performed as described (Liu et al. 2008).

Patient samples and microarray-based genomic and expression profiling

A total of 63 tissue samples from patients diagnosed with either primary $(n=41)$ or secondary glioblastomas were studied for genome-wide DNA copy number alterations applying arrayCGH analysis. All cases were additionally studied for gene expression on the transcript level using oligonucleotide arrays. The tumors were taken from the archives of the Department of Neuropathology, Heinrich-Heine University of Düsseldorf, and were analyzed in an anonymous manner as approved by the local institutional review board. Further information is included in the Supplemental Material.

\section{Acknowledgments}

We thank Dr. Otmar D. Wiestler for critically reviewing the manuscript. We thank Jan Rodriguez Parkitna, Grischa Toedt, and Meinhard Hahn for support in microarray analysis, and Hui $\mathrm{Wu}$ for assistance in microdissection of tissue samples. This work was supported by the "Deutsche Forschungsgemeinschaft" through Collaborative Research Centres SFB 488 and SFB 636, the European Union through grant LSHM-CT-2005-018652 (CRESCENDO), the Bundesministerium für Bildung und Forschung (BMBF) through NGFNplus grants FZK 01GS08153 and 01GS08142 and project number 0313074C (HepatoSys), the Helmholtz Gemeinschaft Deutscher Forschungszentren through Initiative CoReNe (Network II, E2) and Alliance HelMA (HA-215), and the Deutsche Krebshilfe through project 108567.

\section{References}

Aguirre AA, Chittajallu R, Belachew S, Gallo V. 2004. NG2expressing cells in the subventricular zone are type C-like cells and contribute to interneuron generation in the postnatal hippocampus. J Cell Biol 165: 575-589.

Alcantara Llaguno S, Chen J, Kwon CH, Jackson EL, Li Y, Burns DK, Alvarez-Buylla A, Parada LF. 2009. Malignant astrocytomas originate from neural stem/progenitor cells in a somatic tumor suppressor mouse model. Cancer Cell 15: 45-56.

Alvarez-Buylla A, Garcia-Verdugo JM. 2002. Neurogenesis in adult subventricular zone. J Neurosci 22: 629-634.

Androutsellis-Theotokis A, Leker RR, Soldner F, Hoeppner DJ, Ravin R, Poser SW, Rueger MA, Bae SK, Kittappa R, McKay RD. 2006. Notch signalling regulates stem cell numbers in vitro and in vivo. Nature 442: 823-826.

Antonchuk J, Sauvageau G, Humphries RK. 2002. HOXB4induced expansion of adult hematopoietic stem cells ex vivo. Cell 109: 39-45.

Bao S, Wu Q, McLendon RE, Hao Y, Shi Q, Hjelmeland AB, Dewhirst MW, Bigner DD, Rich JN. 2006a. Glioma stem cells promote radioresistance by preferential activation of the DNA damage response. Nature 444: 687-688.

Bao S, Wu Q, Sathornsumetee S, Hao Y, Li Z, Hjelmeland AB, Shi Q, McLendon RE, Bigner DD, Rich JN. 2006b. Stem celllike glioma cells promote tumor angiogenesis through vascular endothelial growth factor. Cancer Res 66: 7843-7848.

Bickenbach JR. 1981. Identification and behavior of label-retaining cells in oral mucosa and skin. J Dent Res 60: 1611-1620.

Calabrese C, Poppleton H, Kocak M, Hogg TL, Fuller C, Hamner B, Oh EY, Gaber MW, Finklestein D, Allen M, et al. 2007. A perivascular niche for brain tumor stem cells. Cancer Cell 11: 69-82.

The Cancer Genome Atlas Research Network. 2008. Comprehensive genomic characterization defines human glioblastoma genes and core pathways. Nature 455: 1061-1068.

Chojnacki A, Weiss S. 2008. Production of neurons, astrocytes and oligodendrocytes from mammalian CNS stem cells. Nat Protoc 3: 935-940.

Colak D, Mori T, Brill MS, Pfeifer A, Falk S, Deng C, Monteiro R, Mummery C, Sommer L, Gotz M. 2008. Adult neurogenesis requires Smad4-mediated bone morphogenic protein signaling in stem cells. J Neurosci 28: 434-446.

Daou MC, Smith TW, Litofsky NS, Hsieh CC, Ross AH. 2005. Doublecortin is preferentially expressed in invasive human brain tumors. Acta Neuropathol 110: 472-480.

Doetsch F. 2003. A niche for adult neural stem cells. Curr Opin Genet Dev 13: 543-550.

Doetsch F, Garcia-Verdugo JM, Alvarez-Buylla A. 1997. Cellular composition and three-dimensional organization of the 
subventricular germinal zone in the adult mammalian brain. I Neurosci 17: 5046-5061.

Doetsch F, Caille I, Lim DA, Garcia-Verdugo JM, Alvarez-Buylla A. 1999. Subventricular zone astrocytes are neural stem cells in the adult mammalian brain. Cell 97: 703-716.

Donehower LA, Harvey M, Slagle BL, McArthur MJ, Montgomery CA Jr, Butel JS, Bradley A. 1992. Mice deficient for p53 are developmentally normal but susceptible to spontaneous tumours. Nature 356: 215-221.

Fomchenko EI, Holland EC. 2006. Mouse models of brain tumors and their applications in preclinical trials. Clin Cancer Res 12: 5288-5297.

Galli R, Binda E, Orfanelli U, Cipelletti B, Gritti A, De Vitis S, Fiocco R, Foroni C, Dimeco F, Vescovi A. 2004. Isolation and characterization of tumorigenic, stem-like neural precursors from human glioblastoma. Cancer Res 64: 7011-7021.

Gil-Perotin S, Marin-Husstege M, Li J, Soriano-Navarro M, Zindy F, Roussel MF, Garcia-Verdugo JM, Casaccia-Bonnefil P. 2006. Loss of p53 induces changes in the behavior of subventricular zone cells: Implication for the genesis of glial tumors. J Neurosci 26: 1107-1116.

Globus J, Kuhlenbeck H. 1942. Tumors of the striatothalamic and related regions: Their probable source of origin and more common forms. Arch Pathol (Chic) 24: 674-737.

Groszer M, Erickson R, Scripture-Adams DD, Lesche R, Trumpp A, Zack JA, Kornblum HI, Liu X, Wu H. 2001. Negative regulation of neural stem/progenitor cell proliferation by the Pten tumor suppressor gene in vivo. Science 294: 2186-2189.

Groszer M, Erickson R, Scripture-Adams DD, Dougherty JD, Le Belle I, Zack JA, Geschwind DH, Liu X, Kornblum HI, Wu H. 2006. PTEN negatively regulates neural stem cell selfrenewal by modulating G0-G1 cell cycle entry. Proc Natl Acad Sci 103: 111-116.

Hemmati HD, Nakano I, Lazareff JA, Masterman-Smith M, Geschwind DH, Bronner-Fraser M, Kornblum HI. 2003. Cancerous stem cells can arise from pediatric brain tumors. Proc Natl Acad Sci 100: 15178-15183.

Holland EC, Hively WP, DePinho RA, Varmus HE. 1998. A constitutively active epidermal growth factor receptor cooperates with disruption of G1 cell-cycle arrest pathways to induce glioma-like lesions in mice. Genes \& Dev 12: 3675 3685.

Holland EC, Celestino J, Dai C, Schaefer L, Sawaya RE, Fuller GN. 2000. Combined activation of Ras and Akt in neural progenitors induces glioblastoma formation in mice. Nat Genet 25: 55-57.

Ignatova TN, Kukekov VG, Laywell ED, Suslov ON, Vrionis FD, Steindler DA. 2002. Human cortical glial tumors contain neural stem-like cells expressing astroglial and neuronal markers in vitro. Glia 39: 193-206.

Jacks T, Remington L, Williams BO, Schmitt EM, Halachmi S, Bronson RT, Weinberg RA. 1994. Tumor spectrum analysis in p53-mutant mice. Curr Biol 4: 1-7.

Jackson EL, Garcia-Verdugo JM, Gil-Perotin S, Roy M, QuinonesHinojosa A, VandenBerg S, Alvarez-Buylla A. 2006. PDGFR $\alpha$-positive B cells are neural stem cells in the adult SVZ that form glioma-like growths in response to increased PDGF signaling. Neuron 51: 187-199.

Jain RK, di Tomaso E, Duda DG, Loeffler JS, Sorensen AG, Batchelor TT. 2007. Angiogenesis in brain tumours. Nat Rev Neurosci 8: 610-622.

Jin K, Zhu Y, Sun Y, Mao XO, Xie L, Greenberg DA. 2002. Vascular endothelial growth factor (VEGF) stimulates neurogenesis in vitro and in vivo. Proc Natl Acad Sci 99: 11946-11950.

Kanamori M, Kawaguchi T, Nigro JM, Feuerstein BG, Berger MS, Miele L, Pieper RO. 2007. Contribution of Notch signaling activation to human glioblastoma multiforme. J Neurosurg 106: 417-427.

Kippin TE, Martens DJ, van der Kooy D. 2005. p21 loss compromises the relative quiescence of forebrain stem cell proliferation leading to exhaustion of their proliferation capacity. Genes \& Dev 19: 756-767.

Kurusu M, Maruyama Y, Adachi Y, Okabe M, Suzuki E, Furukubo-Tokunaga K. 2008. A conserved nuclear receptor, Tailless, is required for efficient proliferation and prolonged maintenance of mushroom body progenitors in the Drosophila brain. Dev Biol 326: 224-236.

Liu H-K, Belz T, Bock D, Takacs A, Wu H, Lichter P, Chai M, Schütz G. 2008. The nuclear receptor tailless is required for neurogenesis in the adult subventricular zone. Genes \& Dev 22: $2473-2478$.

Louis DN. 1994. The p53 gene and protein in human brain tumors. I Neuropathol Exp Neurol 53: 11-21.

Maslov AY, Barone TA, Plunkett RJ, Pruitt SC. 2004. Neural stem cell detection, characterization, and age-related changes in the subventricular zone of mice. I Neurosci 24: 1726-1733.

Menn B, Garcia-Verdugo JM, Yaschine C, Gonzalez-Perez O, Rowitch D, Alvarez-Buylla A. 2006. Origin of oligodendrocytes in the subventricular zone of the adult brain. I Neurosci 26: 7907-7918.

Modena P, Lualdi E, Facchinetti F, Veltman J, Reid JF, Minardi S, Janssen I, Giangaspero F, Forni M, Finocchiaro G, et al. 2006. Identification of tumor-specific molecular signatures in intracranial ependymoma and association with clinical characteristics. J Clin Oncol 24: 5223-5233.

Molofsky AV, Slutsky SG, Joseph NM, He S, Pardal R, Krishnamurthy J, Sharpless NE, Morrison SJ. 2006. Increasing p16INK4a expression decreases forebrain progenitors and neurogenesis during ageing. Nature 443: 448-452.

Monaghan AP, Grau E, Bock D, Schutz G. 1995. The mouse homolog of the orphan nuclear receptor tailless is expressed in the developing forebrain. Development 121: 839-853.

Monaghan AP, Bock D, Gass P, Schwager A, Wolfer DP, Lipp HP, Schutz G. 1997. Defective limbic system in mice lacking the tailless gene. Nature 390: 515-517.

Morris RJ, Potten CS. 1994. Slowly cycling (label-retaining) epidermal cells behave like clonogenic stem cells in vitro. Cell Prolif 27: 279-289.

Ninkovic J, Gotz M. 2007. Signaling in adult neurogenesis: From stem cell niche to neuronal networks. Curr Opin Neurobiol 17: 338-344.

Orford KW, Scadden DT. 2008. Deconstructing stem cell selfrenewal: Genetic insights into cell-cycle regulation. Nat ReV Genet 9: 115-128.

Paik JH, Ding Z, Narurkar R, Ramkissoon S, Muller F, Kamoun WS, Chae SS, Zheng H, Ying H, Mahoney J, et al. 2009. FoxOs cooperatively regulate diverse pathways governing neural stem cell homeostasis. Cell Stem Cell 5: 540-553.

Parsons DW, Jones S, Zhang X, Lin JC, Leary RJ, Angenendt P, Mankoo P, Carter H, Siu IM, Gallia GL, et al. 2008. An integrated genomic analysis of human glioblastoma multiforme. Science 321: 1807-1812.

Phillips HS, Kharbanda S, Chen R, Forrest WF, Soriano RH, Wu TD, Misra A, Nigro JM, Colman H, Soroceanu L, et al. 2006. Molecular subclasses of high-grade glioma predict prognosis, delineate a pattern of disease progression, and resemble stages in neurogenesis. Cancer Cell 9: 157-173.

Renault VM, Rafalski VA, Morgan AA, Salih DA, Brett JO, Webb AE, Villeda SA, Thekkat PU, Guillerey C, Denko NC, et al. 2009. FoxO3 regulates neural stem cell homeostasis. Cell Stem Cell 5: 527-539. 
Reynolds BA, Weiss S. 1992. Generation of neurons and astrocytes from isolated cells of the adult mammalian central nervous system. Science 255: 1707-1710.

Scherer H. 1940. The forms of growth in gliomas and their practical singificance. Brain 63: 1-35.

Sharma MK, Mansur DB, Reifenberger G, Perry A, Leonard JR, Aldape KD, Albin MG, Emnett RJ, Loeser S, Watson MA, et al. 2007. Distinct genetic signatures among pilocytic astrocytomas relate to their brain region origin. Cancer Res 67: 890-900.

Shen Q, Wang Y, Kokovay E, Lin G, Chuang SM, Goderie SK, Roysam B, Temple S. 2008. Adult SVZ stem cells lie in a vascular niche: A quantitative analysis of niche cell-cell interactions. Cell Stem Cell 3: 289-300.

Shi Y, Chichung Lie D, Taupin P, Nakashima K, Ray J, Yu RT, Gage FH, Evans RM. 2004. Expression and function of orphan nuclear receptor TLX in adult neural stem cells. Nature 427: 78-83.

Sim FJ, Keyoung HM, Goldman JE, Kim DK, Jung HW, Roy NS, Goldman SA. 2006. Neurocytoma is a tumor of adult neuronal progenitor cells. J Neurosci 26: 12544-12555.

Singh SK, Clarke ID, Terasaki M, Bonn VE, Hawkins C, Squire J, Dirks PB. 2003. Identification of a cancer stem cell in human brain tumors. Cancer Res 63: 5821-5828.

Singh SK, Hawkins C, Clarke ID, Squire JA, Bayani J, Hide T, Henkelman RM, Cusimano MD, Dirks PB. 2004. Identification of human brain tumour initiating cells. Nature 432: 396-401.

Smyth GE, Stern K. 1938. Tumors of the thalamus: A clinicopathological study. Brain 61: 339-374.

Stenman J, Yu RT, Evans RM, Campbell K. 2003. Tlx and Pax6 co-operate genetically to establish the pallio-subpallial boundary in the embryonic mouse telencephalon. Development 130: 1113-1122.

Stiles CD, Rowitch DH. 2008. Glioma stem cells: A midterm exam. Neuron 58: 832-846.

Sun G, Yu RT, Evans RM, Shi Y. 2007. Orphan nuclear receptor TLX recruits histone deacetylases to repress transcription and regulate neural stem cell proliferation. Proc Natl Acad Sci 104: 15282-15287.

Tavazoie M, Van der Veken L, Silva-Vargas V, Louissaint M, Colonna L, Zaidi B, Garcia-Verdugo JM, Doetsch F. 2008. A specialized vascular niche for adult neural stem cells. Cell Stem Cell 3: 279-288.

Taylor MD, Poppleton H, Fuller C, Su X, Liu Y, Jensen P, Magdaleno S, Dalton J, Calabrese C, Board J, et al. 2005. Radial glia cells are candidate stem cells of ependymoma. Cancer Cell 8: 323-335.

Uemura A, Kusuhara S, Wiegand SJ, Yu RT, Nishikawa S. 2006. Tlx acts as a proangiogenic switch by regulating extracellular assembly of fibronectin matrices in retinal astrocytes. J Clin Invest 116: 369-377.

Vescovi AL, Galli R, Reynolds BA. 2006. Brain tumour stem cells. Nat Rev Cancer 6: 425-436.

Vick NA, Lin MJ, Bigner DD. 1977. The role of the subependymal plate in glial tumorigenesis. Acta Neuropathol 40: 6371.

Wang Y, Yang J, Zheng H, Tomasek GJ, Zhang P, McKeever PE, Lee EY, Zhu Y. 2009. Expression of mutant p53 proteins implicates a lineage relationship between neural stem cells and malignant astrocytic glioma in a murine model. Cancer Cell 15: 514-526.

Yilmaz OH, Valdez R, Theisen BK, Guo W, Ferguson DO, Wu H, Morrison SJ. 2006. Pten dependence distinguishes haematopoietic stem cells from leukaemia-initiating cells. Nature 441: 475-482.
Yu RT, McKeown M, Evans RM, Umesono K. 1994. Relationship between Drosophila gap gene tailless and a vertebrate nuclear receptor Tlx. Nature 370: 375-379.

Zhang CL, Zou Y, Yu RT, Gage FH, Evans RM. 2006. Nuclear receptor TLX prevents retinal dystrophy and recruits the corepressor atrophin1. Genes \& Dev 20: 1308-1320.

Zhang J, Grindley JC, Yin T, Jayasinghe S, He XC, Ross JT, Haug JS, Rupp D, Porter-Westpfahl KS, Wiedemann LM, et al. 2006. PTEN maintains haematopoietic stem cells and acts in lineage choice and leukaemia prevention. Nature 441: 518522.

Zhu Y, Guignard F, Zhao D, Liu L, Burns DK, Mason RP, Messing A, Parada LF. 2005. Early inactivation of p53 tumor suppressor gene cooperating with NF1 loss induces malignant astrocytoma. Cancer Cell 8: 119-130. 


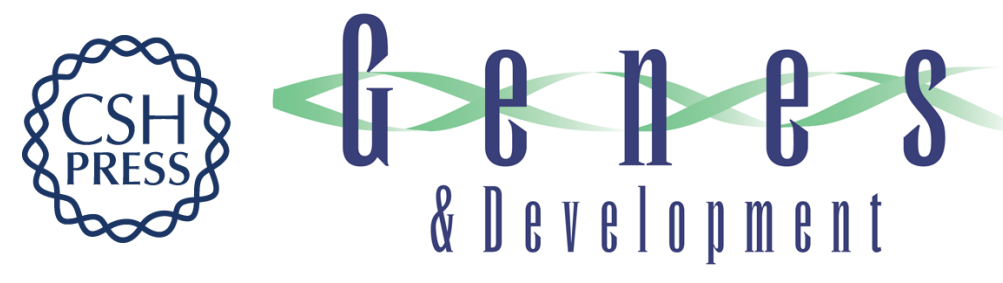

\section{The nuclear receptor tailless induces long-term neural stem cell expansion and brain tumor initiation}

Hai-Kun Liu, Ying Wang, Thorsten Belz, et al.

Genes Dev. 2010, 24:

Access the most recent version at doi:10.1101/gad.560310

Supplemental
Material http://genesdev.cshlp.org/content/suppl/2010/03/31/24.7.683.DC1

References This article cites 72 articles, 27 of which can be accessed free at: http://genesdev.cshlp.org/content/24/7/683.full.html\#ref-list-1

License

Email Alerting

Receive free email alerts when new articles cite this article - sign up in the box at the top Service right corner of the article or click here.

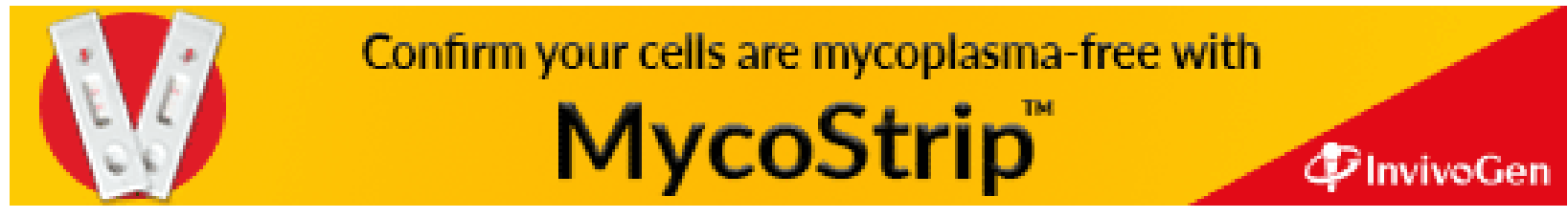

